\title{
Posterior polar annular choroidal dystrophy
}

\author{
Jignesh Manshibhai Gala 두, Raja Narayanan
}

Retina, LV Prasad Eye Institute, Hyderabad, Telangana, India

\section{Correspondence to} Dr Raja Narayanan, narayanan@lvpei.org, dr_narayanan@hotmail.com

JMG and RN contributed equally.

Accepted 13 September 2019

\section{DESCRIPTION}

A 55-year-old female housewife presented with floaters in both eyes. The patient had no significant medical history and was not on any medications, and reported no known drug allergies. The patient had no significant family history. History of night blindness was noted. Fifteen years back, the patient underwent refractive corrective surgery for high myopia. On ocular examination, her best corrected distant visual acuity in the right eye was $20 / 25$ and in the left eye was 20/30 with near visual acuity of $6 / 6$ in each eye. Her external examination which included facial symmetry, external face, head posture, ocular position and ocular alignment was normal. Pupil and anterior segment examination were unremarkable. Goldmann applanation readings were $14 \mathrm{~mm} \mathrm{Hg}$ in the right eye and $12 \mathrm{~mm} \mathrm{Hg}$ in the left eye. Ophthalmoscopic examination through dilated pupil revealed clear media in each eye.

Fundus examination of each eye showed peripapillary chorioretinal atrophy extending to involve temporal vascular arcade forming an annular pattern and sparing fovea. The area of atrophy extended nasal to the disc in both eyes. Atrophy was more extensive in the right eye compared with the left eye. The disc

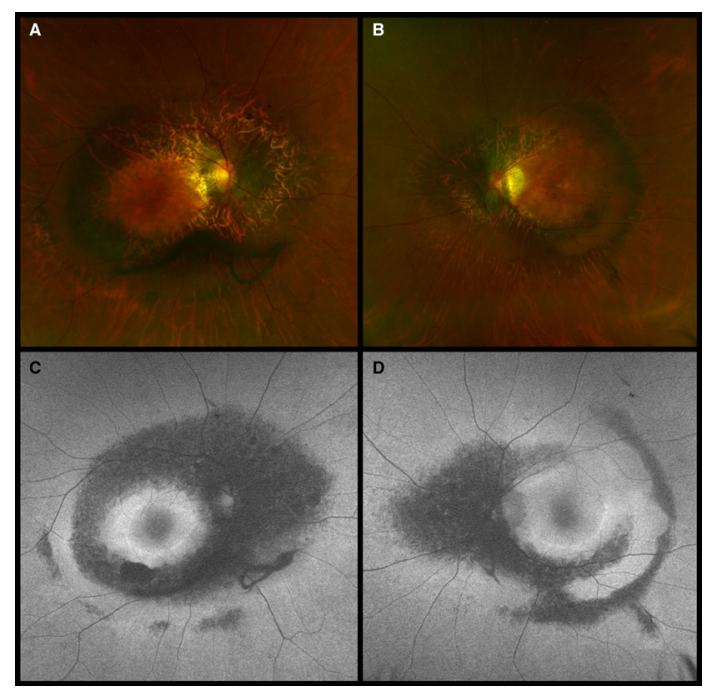

Figure 1 The posterior pole of each eye showed chorioretinal atrophy along vascular arcade in an annular pattern with sparing of the fovea ( $A$ and $B$ ). The area of atrophy was more nasal to disc compared with temporal to disc. Image (A) of the right eye showed extensive involvement than the left eye in image (B). Autofluorescence (Optos, Marlborough, Massachusetts, USA) showed loss of autofluorescence in the area of chorioretinal atrophy with hyperautofluorescence in the primacular area ( $C$ and $D)$. The annular pattern was complete in the right eye and incomplete in the left eye which shows the asymmetric nature of the disease.

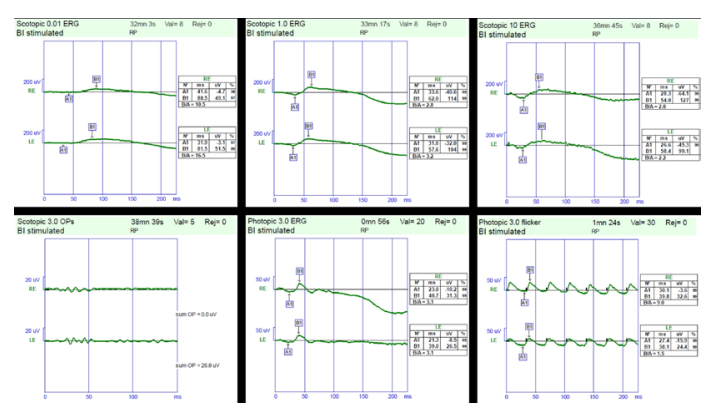

Figure 2 Electroretinography (Metrovision, Pérenchies, France) of both eyes showed a reduction in scotopic and photopic a-wave and b-wave and a significant reduction in $30 \mathrm{~Hz}$ flicker response with delayed implicit time.

was healthy and there was no arterial attenuation or no bony spicules. Peripheral fundus examination was unremarkable (figure $1 \mathrm{~A}$ and $\mathrm{B}$ ).

Autofluorescence (Optos, Marlborough, Massachusetts, USA) image of each eye showed loss of autofluorescence along with chorioretinal atrophy. There was a perifoveal hyperautofluorescence in both eyes (figure $1 \mathrm{C}$ and $\mathrm{D}$ ).

Electroretinogram (Metrovision, Pérenchies, France) of each eye showed a reduction in scotopic and photopic a-wave and b-wave and reduction in $30 \mathrm{~Hz}$ flicker response and oscillatory potentials with delayed implicit time (figure 2).

Humphrey visual field 30-2 of showed generalised depressed points, more in the pericentral area in both eyes (figure 3).

Swept source optical coherence tomography (Triton, Topcon, Tokyo, Japan) image of each eye showed normal fovea contour with normal outer and inner retinal structures. However, there was loss of architecture in the area of annular chorioretinal atrophy. Choroidal thinning was noted in each eye (figure 4).

Optical coherence tomography angiography (OCTA) showed normal superficial capillary plexus

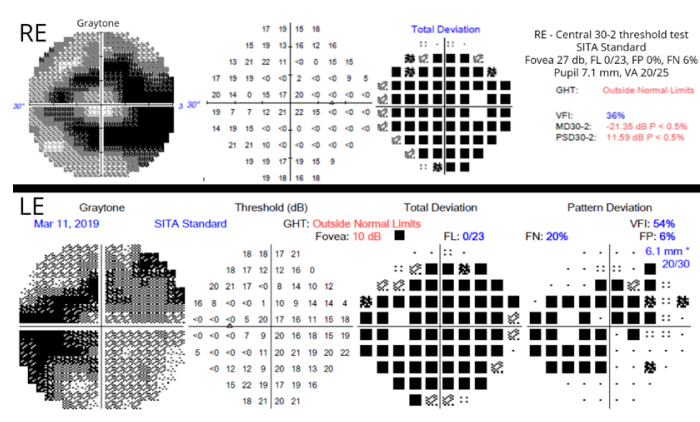

Figure 3 Humphrey visual field 30-2 of the right eye (A) and left eye (B) shows generalised depressed points, more in pericentral area. 

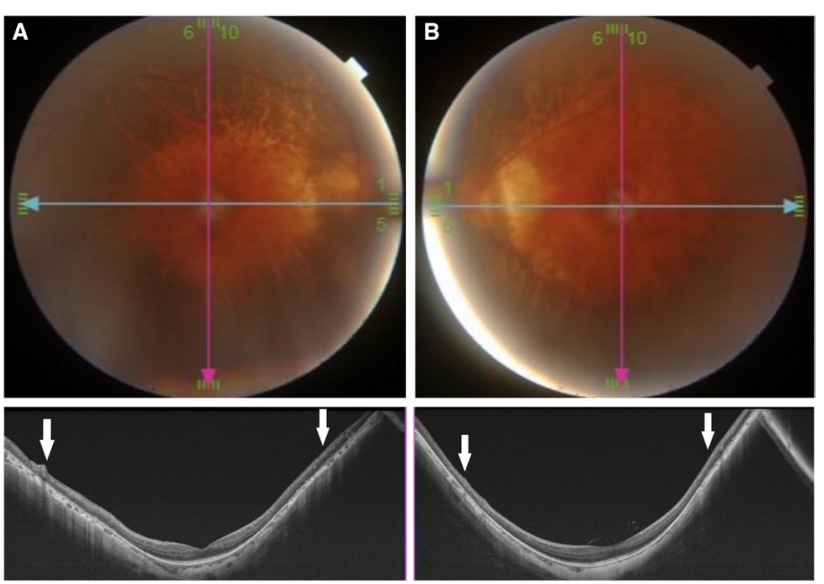

Figure 4 Swept source optical coherence tomography of the fovea, subfovea and choroid was essentially normal as shown in images ( $A$ and B) of the right eye and left eye, respectively. However, there was a loss of retinal architecture in the affected area of atrophy as shown with arrows in the vertical scan.

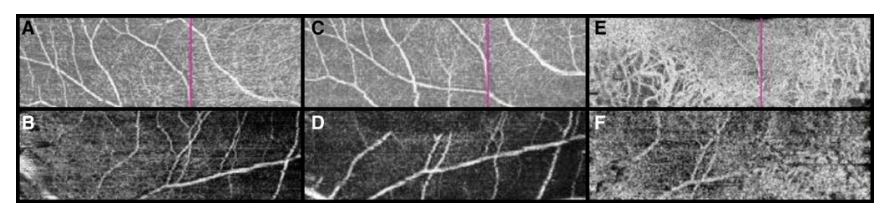

Figure 5 Optical coherence tomography angiography shows normal superficial capillary plexus ( $A$ and $B$ ) of both eyes. However, there was a significant reduction in deep capillary plexus ( $C$ and $D$ ) and loss of choriocapillaris ( $\mathrm{E}$ and $\mathrm{F}$ ) of both eyes in the affected atrophy area.

with a significant reduction in deep capillary plexus and loss of choriocapillaris in the affected area of atrophy in both eyes (figure 5).

Based on the above findings, final diagnosis of posterior polar annular choroidal dystrophy (PPACD) was made.

Primary choroidal dystrophies which affect the central macula are referred to as central areolar choroidal dystrophy, posterior polar central choroidal dystrophy, posterior polar annular dystrophy, posterior polar hemispheric dystrophy and central and peripheral annular choroidal dystrophy. ${ }^{12}$

These dystrophies represent a distinct group of disorder involving bilateral outer retinal, retinal pigment epithelium and choriocapillary atrophy with a characteristic fundoscopic pattern. ${ }^{3} 4$ PPACD is a rare type of choroidal dystrophy which affects the retina and choroid in an annular pattern.

Though bilateral involvement was seen in all cases, asymmetricity is common. ${ }^{5}$ As in our case, the right eye was more involved than the left eye.

The fovea was spared in all reported cases, except one report shows cystoid macular oedema in both eyes in case of PPACD. ${ }^{6}$

Arcuate scotoma corresponding to chorioretinal atrophy area on Humphrey visual field was reported by coauthor in his previous report. ${ }^{5}$ In our case also there was generalised depressed points more in the paracentral area corresponding to the area of chorioretinal atrophy (figure $3 \mathrm{~A}$ and $\mathrm{B}$ ).

Role of OCTA was first described by co-author in his previous report. He reported that the deep capillary plexus of the retina was significantly reduced with the absence of choriocapillary plexus in

\section{Patient's perspective}

I had a high eye power for which I underwent laser in situ keratomileusis (LASIK) eye surgery. I was fine after that. But sometimes I used to feel some black spots in front of my eyes. Also, I have difficulty in seeing during night time. When I came to LV Prasad eye hospital doctor suggested some rare eye disease. As such, there is no treatment for this condition. He suggested regular follow-up. I just do not want to get blind, I will follow his advice.

\section{Learning points}

- Posterior polar annular choroidal dystrophy (PPACD) is recently reported choroidal dystrophy which spares the fovea.

- Annual follow-up to note the progression is warranted.

- Optical coherence tomography angiography shows loss of choriocapillaris.

- Contrast enhancing measures and use of approach magnification for watching television and near work may help PPACD patients.

the affected areas. He also reported that the choroidal vascularity was reduced in the deeper choroid in the affected areas. ${ }^{5}$

In our case also there were loss void signals in chorioretinal slab showing atrophy of choriocapillaris in both eyes.

Though it is a choroidal disease, electroretinography (ERG) finding shows that there is diffuse dysfunction of photoreceptors as described by co-author in his previous report. ${ }^{5}$

To conclude, PPACD is a rare entity. Patients usually maintain relatively good vision as fovea is spared. Some patient may experience a field defect, but it has not been reported symptoms.

Contributors RN and JMG had seen the patient in the outpatient department. RN made the diagnosis and explained the nature of the disease to the patient. JMG prepared the manuscript and approved by RN. Both authors contributed equally in the image collection, finalising final manuscript and choosing images. RN helped in searching for references.

Funding The authors have not declared a specific grant for this research from any funding agency in the public, commercial or not-for-profit sectors.

Competing interests None declared.

Patient consent for publication Obtained.

Provenance and peer review Not commissioned; externally peer reviewed.

ORCID iD

Jignesh Manshibhai Gala http://orcid.org/0000-0002-1397-2699

\section{REFERENCES}

1 Posterior polar hemispheric choroidal dystrophy. Yannuzzi LA, ed. The Retina Atlas Philadelphia: Saunders, 2010:p. 85

2 Yannuzzi LA. Posterior polar central choroidal dystrophy. Yannuzzi LA, ed. The Retina: Atlas: Saunders, 2010:p.85.

3 Lenis TL, Klufas MA, Randhawa S, et al. Posterior polar annular choroidal dystrophy. Retin Cases Brief Rep 2017;11((Suppl 1):):S24-S27.

4 Forte R, Aptel F, Feldmann A, et al. Multimodal imaging of posterior polar annular choroidal dystrophy. Retin Cases Brief Rep 2018;12:29-32.

5 Narayanan R. Posterior polar annular and hemispheric choroidal and retinal dystrophy: Optical coherence tomographic angiography description of a rare case. Indian J Ophthalmol 2018;66:1874-6.

6 Del Valle-Nava F, Sánchez-Ramos J, Hernández-Vázquez A, et al. Posterior polar annular choroidal dystrophy association with cystoid macular edema. Clin Case Rep 2019;7:389-90. 
Copyright 2019 BMJ Publishing Group. All rights reserved. For permission to reuse any of this content visit https://www.bmj.com/company/products-services/rights-and-licensing/permissions/

BMJ Case Report Fellows may re-use this article for personal use and teaching without any further permission.

Become a Fellow of BMJ Case Reports today and you can:

- Submit as many cases as you like

- Enjoy fast sympathetic peer review and rapid publication of accepted articles

Access all the published articles

Re-use any of the published material for personal use and teaching without further permission

Customer Service

If you have any further queries about your subscription, please contact our customer services team on +44 (0) 2071111105 or via email at support@bmj.com.

Visit casereports.bmj.com for more articles like this and to become a Fellow 